\title{
What is conjured when we talk about the everyday lives of gay men?
}

\author{
Edgar Rodríguez-Dorans and Jason Holmes
}

[Edgar] Most of the ideas for this introduction were developed while washing dishes in a flat in Edinburgh. Most of the actual typing of those words happened in the living room of that same flat, where I live with my husband. The flat is in a modern building, located on the ground floor. At the back there is a door leading to a patio and garden, which gives it a feel of a house, in contrast to how I envision an "apartment" - that is, many floors up in a tower block. The interior is all painted in white, and it has various windows that offer different views, some of them to the garden, some into other flats, but without feeling intrusive. My favourite view is from the kitchen window because it frames a generous portion of the sky that I see change from blue into other colours: from blue into pink, then into orange, and from grey into deep blue. This window deserves acknowledgement, as it affords the everyday activity of washing dishes some reflective qualities.

The above scene-setting paragraph might seem a mere background for what is to come: a series of concepts and themes that form an overview of the book. I must clarify that all elements - the city, the flat, the garden, the sky, my ideas about what a flat is, my husband, the act of washing dishes, my thoughts - are more than a background to the contents of this book; they are an illustration of its core elements. Contributors to this book address themes of personal and cultural significance and engage in critical explorations of their social milieus through narratives of their everyday concerns. These narratives show the different contexts in which gay men live, how these social realities intertwine with our lives at a personal level, and how, in doing so, gay men create, reproduce, question, and challenge the cultures they/we are part of. In my case, the city of Edinburgh is relevant because it is a relatively new place to me, one that has given me perspective: a place I moved to for studies (as did Jason) and the one where I became - without noticing - an immigrant. The flat is relevant because throughout my life growing up in Mexico, I lived in big houses with complex dynamics, which contrasts with my current experience living in Scotland. One of the houses of my childhood was a multi-family house inhabited by nearly 20 people $-\mathrm{a}$ humble construction with a greenhouse full of plants that would be later sold at the town's market in the south of Mexico City. Another house had 


\section{Edgar Rodríguez-Dorans and Jason Holmes}

a wild and lush garden that engulfed the building, creating an exotic feel. I remember that my grandparents would host guests from South America for long periods in that house. Another one was some sort of a mansion with high ceilings and domes that created echoes in its rooms, giving it a church-like atmosphere. Another home was a four-storey house with a view over a small woodland area. My mother and I lived there even though, for two decades, it was an ongoing project, a house constantly under construction. We persisted with the construction partly because it was a dream of autonomy and independence, partly because it was the grounds where generations before us had lived, and we had some family connection with the land. These are just some of the houses I have lived in with peculiar living arrangements. The flat in Edinburgh is the first place I have ever lived that is compact, finished, and 'straightforward'. It is also the first place that I have lived in as a married man. Considering the battles that people have endured to get to this point and the current state of affairs in same-sex relationships around the world (see Mendos, 2019), two men living as a married couple is at the same time an ordinary and extraordinary occurrence.

At the time of co-editing this book with Jason, my everyday life - like many other people's during the global COVID-19 pandemic - revolves around domestic life, and this is something that has surely informed my interest in what happens at the interior of these relational spaces. However, this focus on the intimacy of personal life emerged long before the pandemic. This description of household experiences intends to invite you to pause and stay close to the personal histories narrated in this book and reflect on how these are embedded in a web of inter-personal, social, and cultural dynamics. 'The Everyday Lives of Gay Men' first draws upon Henri Lefebvre's Critique of Everyday Life (2014) to explore ordinary aspects of existence that have been neglected in society at large, but even more in LGBTQIA+ populations. In the context of the series 'Transforming LGBTQ Lives', this book contributes to create and share the stories about gay men's lives that are available as the chapters engage with the psychic, social, geographical, and political dimensions of everyday life from an interdisciplinary perspective. This book looks at the interior of gay men's subjectivities in areas that have not been widely discussed, and, in doing so, it disrupts the common notion that the study of gay men's lives is limited to the field of sexuality studies.

Thus, the different buildings I have inhabited, those relational spaces are more than the backdrop of a life; they are an integral part of life. The different household configurations and the relationships that exist there contributed to and developed my idiosyncrasies. I adapted to periods of life in which we would not have things - for example a fridge - that in other contexts were considered standard; I adapted to spaces where everything would be shared; and I did not question aspects of life I now consider essential - for example, privacy and silence were not a right, but more an occasional luxury when everyone had gone out. Gradually I moved from organic, rural houses 
to what I see as more structured, urban ways of living. Living through these contrasting milieus attuned me to different ways of inhabiting spaces. But beyond my personal experience of the space, these differences were part of a cultural move towards modernism. Flores Rodríguez (2019) writes that domestic life has been one of the main symbols of modernism. My narrative of inhabiting spaces may speak about how sometimes, without noticing, individuals inhabit spaces that are the target of broader social changes led by economists, architects, and urbanists. And if we have the luxury, we may transform those houses into personal spaces, into our homes. A significant part of life happens within the confines of houses, which is why these relational spaces we have inhabited are an element that will be present in this book. As Barak (2019) writes: 'my childhood neighborhood seems to capture a delicate intersection between identity, place, and space, highlighting - as I see it - the role of borders in regulating identities' (p. 667). Domestic life is one of the focuses of this book, not only because relationships, events, memories, and existence itself happen at the crucible of domestic life but also because it illustrates aspects of social, cultural, and political relevance.

From the private spaces of homes, this book also focuses on queer ways of relating to friends, to partners, and to other family relationships, always seeking to look at gayness both as culture and identity, from a close-up perspective, always from a first-hand perspective in which it is gay men who give an account of what it means to be gay; how we make relationships, love, and community; and how we make our worlds at the intersection of other people's worlds. Our gayness is the lens through which we think about culture. 'The everyday' or what happens as quotidian experience is shaped by our individuality; what is mundane and ordinary for me - Edgar - is not ordinary for you reading this text. My everyday consists of waking up at 8 a.m., having my shower, having breakfast, and, amidst the COVID-19 pandemic, going to a little corner in the flat where I listen to people in my online mental health practice, writing notes, writing for academic projects - this very text I'm writing right now is a good example of my everyday life. I have a series of routines like having coffee, watching movies, gathering virtually with friends to dance, joking with my husband, clearing the table so we can have dinner, clearing the table after having dinner so it can double as my office desk the following day, washing more dishes, taking the rubbish to the bins (and worrying about how much plastic we produce), 'WhatsApping' with my mother and my friends. Then I repeat these routines the following day and the day after that. I know everyday life during the COVID-19 pandemic is similarly restrained for Jason too.

In his exploration of the everyday, Ben Highmore (2017) questions:

What exactly is being invoked when we call on the everyday - a terrain of habit, survival, getting-by and getting-on, or going under? Perhaps it presents a sphere of desire and feeling - hopes dreamt of and pursued, or dashed on the rocks of prosaic reality, or a world of pervasive 
and sporadic moods (e.g., anxiety, boredom, elation, barely concealed rage)? Or something more like a quantity than a set of qualities: this much sleep, that much food, this much work, that much money, these many days left...?

In this book, the everyday encompasses the realm of habits and routines a continuous sense of doing - that is conflated with an equally important sense of feeling and thinking. The significance of the everyday comes into play when we realise that the minuscule aspects of experience come together to form the grand narrative that is our lives, such as me writing this and you reading it right now. The events we remember the most are those 'grand' events of our lives: for me, the day I experienced my first gay kiss, the day I left Mexico and moved to Scotland, the day my beloved friend died. What are the grand events of your life? I presume you remember a few. However, we might forget the more mundane aspects of life. It is paradoxical that it is in those ordinary moments, those that seem uninteresting, that we might find unexpected value. This effect, this focus on the milestones, happens similarly at a broader social and cultural level. We remember big dates, big events, big achievements, big challenges. In his book, Queer Domesticities, Cook (2014) writes about his interest in showing:

additional ways in which queer men orientated their sense of themselves - behind closed doors and apart from the more public bars, clubs, toilets, cruising grounds, courtrooms, and protest and pride marches that have more often drawn our attention. It takes queer histories more determinedly indoors, and touches and troubles existing histories of home and family which almost entirely neglect queer lives.

Intimacy is an essential concern of authors writing for this collection. This intimacy takes us behind closed doors, inside the spaces we make our homes, but this same intimacy also goes beyond the materiality of those walls and buildings to address the relationships - with the self and others - that come into being within those spaces. We reveal rare aspects of life, aspects of gayness that have been ignored, sometimes even by ourselves. We emphasise that the point of departure for the essays in this collection is a personal experience and how this is embedded in dynamic relationships in our respective social contexts. Our focus, therefore, is on the large, intricate, detailed life stories and the ways in which gay men give meanings to those stories. Our intention is for these narratives to contribute to the creation of ordinary representations of gayness from an insider perspective.

\section{Narrating 'the everyday'}

[Jason] In offering a description of his household experiences, Edgar conceptualises the everyday as something done and thought. His story of life 
inside his flat offers an activity-based account of personal space and the broader narratives within which his story is told. However, the everyday can also be conceptualised through affective engagement - through feelings and experience.

A key challenge when writing about 'experience' is how we can know about, or generate, knowledge of it. On most understandings, 'experience' is intrinsically elusive and never matches our descriptions. In some framings, for example Gendlin's (1959) privileging of present time 'experiencing', part of its elusiveness comprises the experiencer's own inability to describe their experience without losing core features of it. So, in a collection of personal stories, we can also conceptualise 'experiencing the everyday' as encountering, observing, and taking part in events associated with the ordinary 'through which one has lived and gained learning from' (Tudor and Merry, 2002, p. 52). In so doing, the term 'experience' recognises that the learning taken from the events resides inside the individual as a dynamic fusion of thoughts, insights, perceptions, bodily feelings, and emotional responses. Through participating in and learning from events, individuals experience the experience. Experience is, therefore, a blend of two components: (1) the present, the thoughts, insights, perceptions, bodily feelings, and emotional responses arising when the experience is lived, and (2) the past, namely what is remembered as having been present at the time of the initial event (Tudor and Merry, 2002). Hence, when I recall entering my first gay bar, I remember the nervousness I experienced then, and when writing about it now, I feel a tightness in my chest: thus, anxiety lives on inside me or as something yet unknown. In summary, we can also conceptualise the everyday as the totality of the present and past cognitive, physiological, psychological, and spiritual learning the contributors to this collection, gained from encountering, observing, and taking part in their ordinary, mundane lives as gay men.

Authors in this collection address the everyday - the 'ordinary' - in different ways. Some of them do so with an emphasis on the maelstrom of doings and goings-on of their activities, a constant movement that sometimes allows little space for reflexion. There is personal significance in these activities as they fill our minutes, hours, days, and so on. They fill our years with verbs of varied quality and intensity: waking, eating, drinking, talking, sitting, browsing, exercising, earning, and perhaps also some struggling, hurting, crying, longing, missing. The everyday actions we engage in - you reading this sentence right now - constitute the life we are living. This book brings those small actions into focus, allowing us to examine how they construct what we understand as the overarching narratives of our lives. But in between the steady pace of everyday life, in our daily encounters with routine and monotony, we can also find interruptions to the motion, a pause in which we might reflect, a comma. The interruption might afford 
an engagement with our own feelings and thoughts to interpret what the motions mean.

People use those junctures to reflect on the events and make sense of them. This action is rooted in our narrative capacity: that human ability to communicate our experiences in the form of stories and give meaning to them through narrations of those stories (Bruner, 1986; Ricœur, 1984). In the narrative process, people use different devices which help them to organise the random material that emerges from their daily experience (Mayer, 2014). Turning points, kernel moments, stories of redemption, stories of victory: these are all some of the 'tools' that set a milestone in the individual's life as a way of setting beginnings and endings in the continuity of their lives (Phoenix, 2014). Gay men give meaning to gayness partly from cultural and social dimensions and partly from personal experiences, but the grand narratives that shape cultural understandings of gayness often colour these experiences in a way that neglects to reflect personal experience and personal narrative. In her study on histories of LGBTI rights, Lalor (2018) writes: 'A grand narrative must necessarily privilege some views and voices over others, and it tends to do so in relation to a vector of power, which guides perception of situations, representations, and identities' (p. 24).

One of the 'grand narratives' in the lives of gay people is the 'coming out', which makes reference to the moment when an individual acknowledges to others that they identify as gay. It can be communicated to just one friend (Poteat et al., 2009), to their parents (Lee and Lee, 2006); or it can be a public announcement to millions of followers on social media (Stone, 2013) or to the international press (Neate and Hern, 2014). One of the key features about the narrative of the 'coming out' is the act of externalisation, a social aspect of communicating it to someone. Although it is seen as a moment in which the person tells one or more people they are gay, for the person who is telling it, there is normally a process of self-acknowledgement which involves deliberation and deep thought about when, where, how, and to whom to tell it (Adams, 2011; Bolen, 2014; Carnelley et al., 2011). Coming out can be an important event in a person's life, to the extent that it has become one of the grand narratives of the LGBTQIA+ experience. However, anyone who has come out realises that it is not a one-off event, and we come out in different circumstances and contexts so many times throughout our lives, that at points it may even become demoted from grand to ordinary, 'from ritual to gestural' to the realm of 'habitual repetition' (Lefebvre, 2014, p. 137), and other aspects of life might become more important. Thus, some coming-outs feature in the pages of this book (see the foreword by Ken Plummer) because they form part of many gay men's lives (for an insightful analysis of gay identity and the closet, see Adams, 2010). The nuances of these coming-outs will show the need for diverse representations of gayness, and the multiple circumstances in which they occur will demonstrate that even this seemingly well-known aspect of gay life needs further exploration. 
Unsurprisingly, for gay men, being gay is our everyday. Although sometimes we might not actively think about it, it is brought to our consciousness for different reasons, perhaps through one of the moments that form part of the grand narratives, perhaps through an unprecedented event. This book addresses those narrative junctures that help us make sense of who we are. When we live through the experience of loving someone, of being rejected, of waiting for a call from someone, of crying for the loss of someone, of being in touch with our friends or families, of dealing with discrimination, trauma, or abuse; it is through transforming those happenings into stories that we make culture as we speak.

\section{Approaching gayness autoethnographically}

These essays focus on the premises of autoethnography as methodology and draw on the experiences of 12 individuals who address their thoughts, feelings, and stories about finding gayness in their everyday life. Autoethnography is an effective approach to addressing the everyday because it allows the individual to access aspects of culture and society that are only reachable through the self. Understood as 'narratives of self', autoethnographies are 'highly personalised accounts that draw upon the experience of the author/researcher for the purposes of extending sociological understanding' (Sparkes, 2000). Aiming to understand how gay people construct culture and how culture informs gay people's subjectivities, studies from this approach rely on the authors' voices as 'native experts', as 'insiders' of the gay culture. Ellis, Adams, and Bochner (2011) explain that 'once at the service of the (White, masculine, heterosexual, middle/upperclassed, Christian, able-bodied) ethnographer, indigenous/native ethnographers now work to construct their own personal and cultural stories' ( $\mathrm{p}$. 278). These personal and cultural stories become first-hand knowledge that confers authenticity and authority to these studies.

A personal story is the point of departure to analyse aspects of everyday life at various layers of complexity. Because we are aware that by using the term 'gay men', we are invoking a number of assumptions about gender, culture, history, and geopolitics, we want to open the term for interrogation. We use a queer prism to observe how this identity colours our experiences and makes those experiences specific to gay men. As Spieldenner and Eguchi (2019) write: 'The queer praxis of autoethnography calls out the politics embedded in the narratives: it is a matter of making visible the invisible forces that undergird all social interactions and experiences rooted in heteronormativity' (p. 135). Being gay is political - even when it is not intended to be - and there are many ways of being gay. While there are aspects of gay culture that are widespread throughout the world and are incorporated into our behaviours - some of them even make their ways into non-gay communities - it would be a mistake to think about a universal way of being gay. To better understand what it is like to be gay from 
an ordinary, autoethnographic perspective, contributors write about their reflections of gay identity/culture and its impact on everyday life.

\section{Gay men's lives beyond the grand narratives}

What does 'being gay' mean to gay men? How does being gay manifest itself in our everyday lives? To answer these questions, contributors in this collection focus on the small, the seemingly insignificant, the quotidian; those events, thoughts, and feelings that might go sometimes unnoticed but have the power to affect us, especially when we reflect upon them. Highmore (2017) writes: 'we might do better to treat everyday life as an invitation to consider how we might know the world' (p. 327). That was the approach we asked contributors to take; an invitation to write about something ordinary that had personal significance to them. Their biographical configurations would offer a personal perspective, a way in which they know the world. The exploration of how the everyday might look for gay men living in different cultural contexts would illuminate often ignored aspects of existence. Applying a gay lens or a queer lens to analyse everyday life means that the contents of this book will be familiar to many readers. Authors write about mundane activities - such as waking up and having a shower; travelling in trains, buses, and planes; and going to work, school, or university - and about familiar feelings, such as falling in love, experiencing anxiety, feeling lost. However, these events and feelings will be experienced differently in response to their specific biographical configurations. In other words, what might be ordinary or everyday for Edgar - writing these lines at home in Edinburgh while listening to Paloma Faith and thinking about a loved friend who is gone from the world - might be quite extraordinary for you, who will be reading this book somewhere else in the world while dealing with your own everyday concerns. The expectation is that you find in the experiences narrated in this volume some familiarity, but also that you discover aspects of gay life that you did not know existed.

The 'ordinary' as an angle to approach meaningful discussion presents a problem inherent to the term itself in the sense that something ordinary is something with no special characteristics, something commonplace which, consequentially, does not seem worth writing about. Writing about the unremarkable seems counterintuitive as we wonder who would be interested in reading such text. This is where reflexivity enters into the picture, as the invitation for authors to look into their own experiences and disrupt the familiarity with the events of their own lives has the potential to transform their own understanding of what it means to be gay. Taking a reflexive stance on everyday life invites us to look at the structures that sustain those routines, those common thoughts, and those ordinary effects. On his 'Critique of Everyday Life', Lefebvre proposes an imaginary scene, of a woman who buys sugar, to analyse the interconnectedness of personal life with broader social and cultural issues. The apparently simple scene is 
connected to circumstances that go beyond the woman herself, as the act of buying sugar responds to her individual needs and desires but also to broader social spheres that surround the act. In a similar vein, we propose an imaginary scene of a gay man browsing the LGBT section on Netflix. While the act can be seen as a response to the individual's desire to watch LGBT content, this need is tied to a geographical location and a period in history in which watching lesbian, gay, bisexual, and transgender content is not only possible but perhaps it is also ordinary. This act also responds to a technological revolution that has made it possible for entertainment to be distributed digitally. Commercial implications can also be considered, as these contents are delivered by companies with an interest in profit. Questions of technology and internet access are also relevant. Amidst these broader social conditions, there are individual processes while the man browses that section. He might be thinking that the category 'LGBT' is missing the ' $Q$ ', the 'I', the 'A', and the ' + ' that represent a wider range of identities under that rainbow; he might be thinking that Netflix got it wrong because some of the content does not even belong in that section. Or perhaps the man is just happy to see some relatable content. He might be thinking about his own personal history and how this content was not available when he was a teenager. Perhaps this fictional character is not a 'he' but a 'they'. Perhaps they are not even gay but queer. Perhaps they even question the label 'man'. Perhaps they dread the way in which LGBTQIA+ identities have been commercialised and presented as products to be consumed. Perhaps they worry about how particular stories are largely ignored while others are repeated over and over, mystified and presented as accurate realities of the lives of these populations.

This book engages with those widely accepted 'realities' of the lives of gay men and interrogates the elements that maintain them because, in many societies, gay men have lived under oppressive regimes that have shaped our ways of communication. The 'gay gaze' is perhaps one of those common practices of gay cultures: an act of secret intimacy in plain sight. It starts with delighting in the eye candy, looking at guys who most of the time do not look back. But sometimes they do. And when they do look back, we might experience the power of possibility through an act of recognition, a sense of reciprocal desire - a simple gaze, a mutual encounter of eyes that validates our identities and corroborates our very own existence. I - Edgar - experienced and practised the gay gaze way before I even had a name for it; I would long for that moment when someone would look back at me. That would be my everyday. For years I would look for those encounters of eyes without even knowing that researchers had created a label for it. In contexts where talking about being gay - and even identifying oneself as gay - represents a risk, the act of looking at men and sensing whether they will look back becomes, for many gay men, an essential form of communication. Another common aspect of gay cultures has been centred on night clubs and the activities around them - dancing, drinking, flirting, congregating 
with others who are 'like us'. In many contexts around the globe, there are similar versions of the gay night club, with its rainbow flag on the door and its 'gay music'. While there might be 'global gays' who ascribe to these aspects of culture, it is important to emphasise that gayness is an ambiguous concept for which there is no uniform worldview. What there is, is a set of grand narratives about gayness that have been formed by powerful forces such as the state, capitalism, religion, and science and have shaped people's understandings of what being gay means.

Applied to the field of queer studies, some of the grand narratives describe LGBTQIA+ peoples through perils, conflicts, and suffering (Lalor, 2018). Research has also been complicit in incomplete portrayals of LGBTQIA+ life; sociological, psychological, medical, and legal disciplines refer to LGBTQIA+ people in terms of sexual orientations, sexual identities, sexual minorities, and gender identities. Along with the notion of sexuality being at the centre of LGBTQIA+ life - in particular gay men's lives - there is another grand narrative that creates a false dichotomy between heterosexuality and everyone else who is not heterosexual. This means that the whole diversity of LGBTQIA+ identities is often referred to as 'the non-heterosexual population', as if the term LGBTQIA+ existed only in function of heterosexuality. These grand narratives position LGBTQIA+ individuals in a disadvantaged place, defining entire populations as an ambiguous 'other' and often forcing the focus to sexuality while important aspects of everyday living are neglected. Being gay is about more than sexuality, and the chapters of this collection will show how gayness intertwines with work and employment, migration, globalisation, and climate change. Contributors invite you to look at aspects of gayness that often go unnoticed in dominant discourses.

\section{On the everyday stories of this book and the authors who wrote them}

From an autoethnographic approach, this collection is concerned with how gay men give meanings to their everyday experiences and how, through those meanings, they/we create their/our life story. To create this collection, we invited 12 individuals working in different fields and from different backgrounds to write an essay based on personal experience. Diversity has been a guiding principle of this project. Acknowledging the various ways in which diversity can be conceptualised, we followed Harrison and Klein's (2007) assertion that diversity is 'attribute specific' (p. 1200). This means that a group might not be inherently diverse, but instead a group is diverse with respect to a particular feature or set of features. Thus, we aimed to create a diverse collection in terms of two different attributes: biographical configurations and disciplinary perspectives. In terms of biographical configurations, we sought contributors of various ages and from a variety of cultural contexts. They bring their history with them and touch upon 
aspects of geography, religion, ethnicity, and nationality. They write about their experiences of being gay in the UK, USA, Turkey, Thailand, Mexico, Ireland, and Namibia, and they address, sometimes in very subtle ways, the broader social aspects that shaped their individual experiences. In terms of disciplinary perspectives, we aimed to present a variety of thoughts and disciplines in the collection. Some authors come from a post-humanist approach; some of them come from the arts and humanities, mental health professions, and some from a more general social science background. In some cases, we knew the contributors; in some other cases we only knew their scholarship, and that is how we decided to approach them. However, we are not under any illusions that we are presenting a completely diverse collection; for example, we are mindful that we are still presenting a cisgendered, westernised view of being gay men, but we always aimed to achieve a collection that takes the ordinary, the mundane, the everyday in our lives as gay men as the departure point to address the concept beyond the grand narratives that have dominated representations of gay life. We considered the contributors' expertise and invited them to use that as an angle to approach their writing. However, we emphasised they could take their chapter in any direction they so wished.

The result of these contributions is a collection of 12 autoethnographies and a series of reflective notes on the writing process. The autoethnographies are organised in a way that evokes certain contiguity in their messages; the chapters speak to each other while maintaining the personal and disciplinary imprint of the authors. Organised around the notion that gayness is experienced at intra-personal, relational, and social levels, the chapters move from a more intimate domesticity - the book opens with a chapter that takes us to the moment of waking up, being in bed with the author - and towards a wider social, cultural, and global narrative - the book finishes with a chapter that makes us think of the impact of modern life in the global environment. We resist the notion of thinking of the contributions in terms of abstract themes. Instead, we invite the reader to connect with the individual stories and stay with the people who wrote them. This approach aims to understand individuals and their specific life circumstances.

In the first chapter, David Lowbridge-Ellis presents 17 examples of how being gay infuses his professional, social, and married life, offering a rich narrative of the centrality of gayness in his intra- and inter-personal relationships. The diversity of examples portrayed in the chapter provide some well-known passages of gayness such as 'coming out' from a new angle, making the familiar unfamiliar, such as an understated coming out to an assembly. The chapter gives a rare insight into school life from the perspective of a teacher and articulates feelings that will resonate with a number of gay men beyond a professional perspective.

Randall C. Lopez writes an emotive autoethnography that provides rich descriptions of aspects of love, loss, and grief. Framed within the space of the shower room, the personal experience narrated by Randall invites you 


\section{Edgar Rodríguez-Dorans and Jason Holmes}

to closely examine the processing of emotions in the event of their father's passing and the end-transformation of a romantic relationship. The unfolding of the father-son relationship reminds us of the many family relationships that are still impacted by prejudices and stigmatisation of gayness and, although Randall contextualises it from the perspective of a MexicanAmerican family, this scenario will speak to readers from different cultural backgrounds.

Panu Sahassanon introduces the reader to his personal Christmas as a celebration of togetherness in Thailand. This holiday has links both with his early recollections of family life and also with his more recent friendships, like a festivity that gives the opportunity to integrate all his relationships during the December-January period. Taking us through experiences of different Christmases, the chapter presents an element of Christianity in focus in a predominantly Buddhist country. The chapter also brings our attention to thinking beyond the Western construction of gender and sexuality and reflecting on how Thai culture provides with its own construction and performance of gender and sexual identities.

In 'Sunday: An intimate account of loneliness', Cináed Thomas writes about his lifelong sense of isolation. Using self-dialogue, Cináed tells of the excruciating desolation he often goes through on Sundays, when families and friends are involved in their own domestic lives. Reflecting on recent family deaths, Cináed then ponders on his usefulness to others and himself if, as others have commented to him, 'he doesn't have a family'. In often painful and self-disclosing writing, Cináed reflects on what relatives have said to him at the time these relatives died and delves into his wish not to receive treatment should he develop a life-threatening illness.

In 'On (not) living past 30' Tony E. Adams discusses a pervasive view of ageing amongst gay men, one in which ageing is seen as a negative and undesirable process. Narrated in the second person, the text introduces his relationship with his long-term friend/family/lover Brett to reflect on the cultural and circumstantial forces that have constructed an image of youthful, often tragic, gayness. Through the tragic premonition 'I'll be dead by 30 ' in the voice of Brett, the text illustrates the lack of cultural narratives/ trajectories/scripts for gay men after 30, yet at the same time presents more hopeful alternatives.

In 'Going back to the glory hole: An everyday story from the therapy room', Seamus Prior presents a narrative of the personal challenges faced when working with gay men in the therapy room, in particular when addressing sexual content. It is an example of the subjective experience of a gay male therapist encountering feelings that are never a 'once done thing'. The theme of the glory hole is affective and thought-provoking, as Seamus invites readers to reflect with him on a symbol of gay culture that will be identified by many. This work is of particular interest to an audience of mental health professionals as it demonstrates that, while in theory any qualified psychotherapist could work with gay men, there is certain 
sensitivity and specialised knowledge of gay culture that is required to work effectively with this population.

In 'Becoming (in)visible: On mental health, help-seeking, and missing connections', Willem J. Stander presents a performative autoethnography on the theme of mental health difficulties and the personal, social, and cultural barriers to accessing mental health services. Set in the form of a theatre piece, the stories portrayed are based on embodied knowledge, as we read about knees giving out, holding hands, tearing eyes, fingers interlacing from the perspective of a white, middle-class gay man. These narrated actions provide a wide range of subtle imagery of how the body expresses what otherwise would be private emotions. Within the large group encompassed in the umbrella term 'LGBTQIA+', 'Becoming (in)visible' draws the reader's attention towards the specific circumstances of students in higher education settings and provides a close-up look at the difficulties that are common to gay men in particular. The chapter makes a subtle yet powerful critique on hegemonic masculinities and invites the reader to reconsider traditional notions of being a man.

In his chapter, Yasin Koc uses the concept of 'ordinary privileges' to construct the main argument about the parallels between someone's ethnic background and someone's sexual orientation/gay identity when navigating systems that favour whiteness and heterosexuality. Yasin selected passages of personal and cultural relevance that bring about the ordinariness of life through scenes of everyday interaction - some of them in a striking way and others in a more delicate manner.

'I dreamt of a stranger' by Julian Triandafyllou is an open and vulnerable text on how his childhood experiences of prolonged sexual abuse have influenced and, to some extent, shaped his ways of relating with gay men. Many of the episodes and settings he describes will be familiar to gay readers and will make the ordinary evident. Julian has shared his ongoing journey into discovering and understanding what being gay means to him and how his experiences have been tainted by the events of child sexual abuse. It was sad and unsettling to read that the abuse became 'ordinary'; however his writing shows his resilience and strength. Furthermore, some of the relationships he writes about, both long-term and ephemeral, demonstrate the restorative power of a meaningful connection.

In 'Testing proximity and intimacy: An everyday reappropriation of private and public space', Edgar Rodríguez-Dorans explains that while sexuality in general has been an area of human life that has been the object of social regulation, gay sexualities have been disproportionately disciplined and oppressed in a way that both public and private lives have been punished. This autoethnography addresses how experiences of relational intimacy have been a crucial factor in resisting public oppression against gay people. Through a narration of a coming-of-age relationship, Edgar argues that intimate ways of relating to gay men have been constructed around fleeting opportunities and unexpected places in response to intimidating, 


\section{Edgar Rodríguez-Dorans and Jason Holmes}

persecutory, and unwelcoming experiences of the public space. Harshness helped the author and his partner discover softness in unexpected places and, in turn, create intimate ways of relating that differed from the normative idea that gayness should be restricted to the confines of private life.

In his chapter, Oscar Pantoja Guzmán uses his personal experience as a Mexican immigrant recently settled in the USA to explore aspects of displacement and mobility through his everyday encounters with colleagues and lovers. He reflects on the discrimination and power imbalance he has experienced in different organisational contexts: as an established organisational psychologist in Mexico City and recently as a sales support worker in California. Through narrations of his journey, he offers insight into the inseparability of his gayness from his everyday life, even in instances where he is not the one thinking about this identity. He concludes by problematising monogamy and using his explorations with polyamory to think about the future of gay men's relationships.

'The Everyday Lives of Gay Men' concludes with 'Planetary times and queer times: A critical planetary Romanticism for the earth' by Whitney A. Bauman, a chapter that pushes the boundaries of the sometimes-insular term 'gay'. Whitney offers the term 'critical planetary romanticism' to expand the obvious ways in which people might think of gay and queer topics. The chapter moves the discourse forward, beyond reductionist ways of seeing gayness and queerness. He disturbs the order of things by making us think about the relationship between fossil fuel economies and the lives that are affected by them (effectively everyone's). He introduces a post-humanist way of loving, one in which it is more important to think beyond a human point of view and recognise other living creatures and the environment, a planetary eroticism. The chapter finishes by offering a future-oriented way of relating, one in which people will be (and some people already are) postlabels, fluid, non-binary, polyamorous. Whitney invites readers to think even further and position themselves towards the future through a polyamory of place.

Written by the editors, the chapter 'Notes on the contributor's experiences' is informed by the authors' experiences of writing their texts. It aims to provide some reflective accounts of the writing process itself and how contributors navigated their autoethnographic research. With this combination of interdisciplinary contributions, the work presented here remains deliberately exploratory and invites you - the reader - to think about gayness in social, cultural, and political terms, as well as in its intra-personal and relational dimensions. The study of gay life requires interdisciplinarity and the autoethnographic approaches used here provided it.

As a whole, this book emerges from those grand narratives, from the conflicted history of sexuality and mental health, and the broader social challenges faced by gay men and other members of the LGBTQIA+ populations. Every single one of those challenges has shaped our understanding of who we are. Those sexual relationships that have defined everything and 
nothing, those legal battles that validate or invalidate those relationships, those legal acts that have been fulfilling and emptying. Those derogative terms - queers, homos, puffs, putos - that first made us feel oppressed but then empowered us. This project emerges from all those well-studied aspects of our lives - the coming-outs, the same-sex marriages, the recognition acts - but it goes beyond that by exploring not only the 'drama' of our lives but also the mundane. Sometimes this book also explores when the drama - and the trauma - became mundane. The project might explore more stories of the struggle of first coming out but also the boredom of coming out for the 100th time; it might look at the big event of attending a pride march but also at the aftermath when people return home to have dinner alone or with friends. The project might look at the perils of navigating public services for marriage licences; it might touch upon the celebration on wedding days, but it also looks at what it is like to be married and living together. This book also looks at those moments when we are alone, troubled, or at ease; it explores those experiences of relationships in seemingly uninteresting contexts to understand how we construct our lives 'day by day'.

\section{References}

Adams, T. E. 2010. Paradoxes of sexuality, gay identity, and the closet. Symbolic Interaction, 33, 234-256.

Adams, T. E. 2011. Narrating the closet: An autoethnography of same-sex attraction. Walnut Creek, Calif: Left Coast Press, Inc.

Barak, A. 2019. My childhood neighbourhood: A critical autoethnography. Qualitative Inquiry, 26, 107780041984356-673.

Bolen, D. 2014. After dinners, in the garage, out of doors, and climbing on rocks. In: Wyatt, J. \& Adams, T. (eds.) On (writing) families. Rotterdam: Sense Publishers.

Bruner, J. 1986. Actual minds, possible worlds. Cambridge, MA and London: Harvard University Press.

Carnelley, K. B., Hepper, E. G., Hicks, C. \& Turner, W. 2011. Perceived parental reactions to coming out, attachment, and romantic relationship views (English). Attachment \& Human Development (Print), 13, 217-236.

Cook, M. 2014. Queer domesticities homosexuality and home life in twentiethcentury London. Basingstoke, UK: Palgrave Macmillan.

Ellis, C., Adams, T. E. \& Bochner, A. P. 2011. Autoethnography: An overview. Historical Social Research/Historische Sozialforschung, 36, 273-290.

Flores Rodriguez, C. E. 2019. Sobre el modernismo en la arquitectura habitacional en México. Una reflexión epistémica. Revista de Direito da Cidade, 11, 277-309.

Gendlin, E. T. 1959. The concept of congruence reformulated in terms of experiencing. Counseling Center Discussion Papers, 5, 1-30.

Harrison, D. A. \& Klein, K. J. 2007. What's the difference? Diversity constructs as separation, variety, or disparity in organizations. The Academy of Management Review, 32(4), 1199-1228. doi:10.5465/AMR.2007.26586096

Highmore, B. 2017. The everyday, taste, class. Chichester, UK: John Wiley \& Sons, Ltd. 


\section{Edgar Rodríguez-Dorans and Jason Holmes}

Lalor, K. 2018. Encountering the past: Grand narratives, fragmented histories and LGBTI rights 'progress'. Law and Critique, 30, 21-40.

Lee, M. M. \& Lee, R. E. 2006. The voices of accepting and supportive parents of gay sons. Journal of GLBT Family Studies, 2, 1-27.

Lefebvre, H. 2014. Critique of everyday life. London: Verso.

Mayer, F. W. 2014. Narrative politics [electronic resource]: Stories and collective action. New York: Oxford University Press.

Mendos, L. R. 2019. State-sponsored homophobia 2019. Geneva: ILGA.

Neate, R. \& Hern, A. 2014. Tim Cook: 'I consider being gay among the greatest gifts God has given me'. The Guardian, Thursday 30 October 2014.

Phoenix, A. 2014. Opening speech, troubling narratives. Troubling Narratives: Identity Matters. Huddersfield, UK: The Institute for Research in Citizenship and Applied Human Sciences, University of Huddersfield.

Poteat, V. P., Espelage, D. L. \& Koenig, B. W. 2009. Willingness to remain friends and attend school with lesbian and gay peers: Relational expressions of prejudice among heterosexual youth. Journal of Youth \& Adolescence, 38, 952-962.

Ricœur, P. 1984. Time and narrative. Chicago: University of Chicago Press.

Sparkes, A. C. 2000. Autoethnography and narratives of self: Reflections on criteria in action. Sociology of Sport Journal, 17, 21-43.

Spieldenner, A. R. \& Eguchi, S. 2019. Different sameness: Queer autoethnography and coalition politics. Cultural Studies, Critical Methodologies, 20, 153270861988496-143.

Stone, J. 2013. Tom Daley: A new way to come out. The Guardian, Tuesday 3 December 2013.

Tudor, K. \& Merry, T. 2002. Dictionary of person-centred psychology. London, UK: Whurr Publishers. 